\title{
PTERIDÓFITAS DA REGIÃO NOROESTE DO ESTADO DE SÃO PAULO, BRASIL: DENNSTAEDTIACEAE
}

\author{
Claudia R. Siqueira ${ }^{1}$ \\ Paulo G. Windisch ${ }^{2}$
}

Recebido em 21/01/1999. Aceito em 23/03/1999

\begin{abstract}
RESUMO - (Pteridófitas da região noroeste do Estado de São Paulo, Brasil: Dennstaedtiaceae). O trabalho faz parte de uma série de estudos sobre pteridófitas da região noroeste do Estado de São Paulo. Os representantes da família Dennstaedtiaceae são encontrados principalmente nas margens das matas ciliares e em barrancos úmidos e sombreados, com exceção de Pteridium que geralmente ocorre em lugares abertos e ensolarados. Ocorrem na região os gêneros Dennstaedtia com duas espécies ( $D$. cicutaria (Sw.) Moore e D. globulifera (Poir.) Hieroni), Lindsaea com três espécies ( $L$ lancea (L.) Bedd., L quadrangularis Raddi e L stricta (Sw.) Dryand.) e Pteridium com uma espécie e variedade ( $P$. aquilinum (L.) Kuhn var. arachnoideum (Kaulf.) Brade). Descriçōes, ilustraçōes, chaves de identificação, bem como distribuição geográfica e habitats de cada espécie são apresentados.

Palavras-chave - Dennstaedtiaceae, pteridófitas, florística, São Paulo, Brasil

ABSTRACT - (Pteridophytes of the North-western region of the State of São Paulo, Brazil: Dennstaedtiaceae). This work is part of a series of studies on pteridophytes of the North-western region of the State of São Paulo. The representatives of the family Dennstaedtiaceae are found mainly at the margins of the ciliary forests as well as in humid and shaded ravines, except for Pteridium which, generally occurs in open and sunny places. The genera Dennstaedtia with two species (D. cicutaria (Sw.) Moore and D. globulifera (Poir.) Hieroni), Lindsaea with three species ( $L$. lancea (L.) Bedd., L quadrangularis Raddi and L stricta (Sw.) Dryand.), and Pteridium with a species and variety (P. aquilinum (L.) Kuhn var. arachnoideum (Kaulf.) Brade), have been found in this region. Descriptions, illustrations, identification keys, geographical distribution, and habitats of each species are presented.
\end{abstract}

Key words - Dennstaedtiaceae, pteridophytes, floristics, São Paulo, Brazil

\section{Introdução}

Poucos são os trabalhos que tratam das pteridófitas do Estado de São Paulo, sendo que as informações, em geral, encontram-se esparsas na literatura taxonômica, havendo poucos trabalhos florísticos. Destacam-se, contudo, as contribuições de Usteri (1911), Brade (1920), Angely (1970), Pereira-Noronha (1989), Salino (1993; 1996),

Herbário SJRP, UNESP, C. Postal 136, CEP 15001-570, São José do Rio Preto, SP, Brasil

2 UNISINOS, CCS-C2 Botânica, Av. Unisinos 950, CEP 93022-000, São Leopoldo, RS, Brasil 
Prado (1997). A carência de coletas de pteridófitas no Estado de São Paulo é abordada por Windisch (1996).

As pteridófitas da flora da região noroeste do Estado de São Paulo são discutidas por Windisch (1992), sendo apresentadas até o nível genérico. O presente trabalho inicia uma série de estudos em que a diversidade específica de pteridófitas ocorrentes nesta região é abordada em detalhe, tratando dos representantes da família Dennstaedtiaceae.

\section{Material e métodos}

A região noroeste do Estado de São Paulo é considerada como sendo delimitada ao sul pelo rio Tietê e à leste, pela linha dos $49^{\circ}$ de longitude.

Foi realizado levantamento nos herbários da Universidade Estadual Paulista, Campus de São José do Rio Preto (SJRP) e Campus de Rio Claro (HRCB), Herbarium Bradeanum (HB), Herbário da Universidade Estadual de Campinas (UEC) e do Instituto de Botânica de São Paulo (SP) para registros das espécies, bem como coleta de dados sobre variabilidade morfológica, distribuição geográfica e habitat dos gêneros e espécies na natureza. Coletas adicionais foram obtidas em excursões na região. Utilizaram-se as técnicas de coleta e preparo de exsicatas descritas por Windisch (1992), sendo o material incorporado aos acervos dos herbários SJRP e HB. As amostras foram comparadas com material determinado por diversos especialistas e com as descrições encontradas em bibliografia especializada: Kramer (1957), Tryon (1941), Tryon (1960), Tryon \& Tryon (1982) e Tryon \& Stolze (1989).

O sistema de classificação é o adotado por Tryon \& Tryon (1982). Na sinonímia, somente estão sendo apresentados nomes aplicados a material originalmente coletado no Brasil. O trabalho apresenta descrições resumidas das espécies. Descrições detalhadas, bem como maiores informações sobre distribuição e ecologia, podem ser encontradas na literatura citada na discussão de cada gênero. As descrições da família e dos gêneros não se restringem apenas ao material da região.

\section{Resultados e discussão}

\section{Dennstaedtiaceae Pichi-Serm.}

Fase esporofítica representada por plantas terrestres ou saxícolas. Caule curto a longo-reptante, ou decumbente a ereto, raro arborescente, com frondes espaçadas a fasciculadas, provido de escamas e/ou tricomas. Frondes monomorfas, raro dimorfas, vernação circinada; estípite sem estípulas na base; lâmina geralmente pinada, raro simples e cordada a sagitada. Nervuras livres ou anastomosantes, com aréolas sem vênulas incluídas. Esporângios agrupados em soros definidos, marginais ou submarginais, raro em posição abaxial mediana ou superficial, sobre terminações de nervuras ou sobre comissura vascular conectando terminações de vênulas; indúsio presente, em forma de taça ou bolsa, ou formado por segmento modificado da margem da lâmina, retroflexo sobre os esporângios, ou indúsio abaxial e estendido lateralmente, ou ainda um indúsio marginal bem desenvolvido e outro interno abaxial, menos desenvolvido (gênero Hypolepis Bernh. sem indúsio); esporângios individuais geralmente com longo pedicelo, com paredes finas (uma camada de células em espessura), ânulo 
longitudinal a levemente oblíquo, interrompido pelo pedicelo, isosporados, esporos desprovidos de clorofila. Fase gametofítica epígea, clorofilada, talo obcordado a reniforme, glabro (Tryon \& Tryon 1982; Windisch 1992).

A família tem distribuição pantropical, com alguns dos seus 17 gêneros estendendo-se às regiões boreal e temperada sul (Tryon \& Tryon 1982). Está representada na região por três gêneros e seis espécies que ocorrem em habitats bem distintos, sendo que as de Dennstaedtia Moore e Lindsaea Dryand. ocorrem principalmente nas margens e interiores de matas ciliares e matas paludosas, bem como ao longo de barrancos úmidos e sombreados. Pteridium Gleditsch ex Scop. tende a ocorrer em locais expostos aos raios solares e em solos de baixa umidade.

Na região não foram encontradas formações densas de Pteridium aquilinum (L.) Kuhn. As demais espécies ocorrem de maneira bastante esparsa e, como não crescem nas matas secas e formações de cerrado que predominavam na cobertura vegetal original, é compreensível a baixa freqüência com que foram coletadas. A extensiva devastação de seus habitats está tornando sua ocorrência ainda mais rara.

Chave para identificação dos gêneros

1. Frondes pinadas a bipinadas II. Lindsaea

1. Frondes bipinado-pinatífidas a mais decompostas

2. Indúsios individualizados, em forma de taça ou bolsa, podendo ser levemente bilabiados; textura laminar herbácea I. Dennstaedtia

2. Indúsios acompanhando as margens dos segmentos férteis; textura laminar, em geral, coriácea

III. Pteridium

\section{Dennstaedtia Moore}

Planta terrestre ou raramente rupestre. Rizoma delgado e longo-reptante, raramente curto-reptante, portando tricomas. Frondes monomorfas, ca. 0,2-4m compr., raramente atingindo $7 \mathrm{~m}$, algumas vezes escandentes. Lâmina em geral herbácea, deltóide, pinada a 4-pinado-pinatífida, lisa ou pubescente (coberta por pêlos finos e curtos), nervuras livres. Soros marginais, algumas vezes com paráfises; indúsio dirigido para baixo, podendo ser levemente bilabiado, em forma de taça ou bolsa.

Gênero tropical e extratropical, com cerca de 45 espécies, sendo 12 delas encontradas na América e que foram revisadas por Tryon (1960).

Chave para identificação das espécies de Dennstaedtia

1. Eixo dos penúltimos segmentos sem aletas herbáceas perpendiculares ao plano do segmento, na superfície superior; ou com aletas, porém estas não decorrentes sobre os eixos seguintes, no lado basioscópico 1.D. cicutaria

1. Eixo dos penúltimos segmentos delimitados em cada lado, na superfície superior, por uma aleta herbácea, resistente e perpendicular ao plano do segmento, sendo estas decorrentes sobre os eixos seguintes, no lado basioscópico 2. D. globulifera 
1. Dennstaedtia cicutaria (Sw.) Moore, Ind. Fil. xcvii. 1857.

Dicksonia cicutaria Sw., J. Bot. (Schrader) 1800 (2): 91.1801.

Dicksonia rubiginosa Kaulf., Enum. fil.: 226. 1824.

Dennstaedtia rubiginosa (Kaulf.) Moore, Ind. Fil.: xcvii. 1857.

Fig. 1

Planta terrestre. Frondes ca. 1-4m compr.; eixo dos penúltimos segmentos sem aletas herbáceas perpendiculares ao plano do segmento, na superfície superior; ou com aletas, porém estas não decorrentes sobre os eixos seguintes, no lado basioscópico. Lâmina herbácea, deltóide, 3- a 4-pinado-pinatífida; pínulas mais ou menos pubescentes adaxial e abaxialmente, tricomas esbranquiçados a acastanhados, curtos e aciculares; nervuras estéreis na superfície inferior, usualmente com extremidades delgadas. Soros com indúsio maduro em forma de taça ou bolsa.

Material examinado: BRASIL. São Paulo: Mirassol, 06/XII/1987, Salino 223 (UEC); Zacarias, Fazenda Santa Irene, 01/VI/1995, Nonato 114 (SJRP); idem, idem, 21/II/1997, Siqueira 101 (SJRP).

2. Dennstaedtia globulifera (Poir.) Hieron., Bot. Jahrb. 34: 455. 1904.

Polypodium globuliferum Poir. in Lam., Encycl. 5: 554. 1804.

Dicksonia globulifera (Poir.) O. Ktze., Rev. Gen. Pl. 3(2): 378. 1898.

Dicksonia tenera C. Presl, Del. Prag. 1: 189. 1822.

Dennstaedtia tenera (C. Presl) Mett., Ann. Sci. Nat. 2: 261. 1864.

Dennstaedtia Tamandarei Rosenst., Hedwigia 56: 359. 1915.

Fig. 2-3

Planta terrestre. Frondes ca. 1-3m compr.; eixo dos penúltimos segmentos delimitados em cada lado, na superfície superior, por uma aleta herbácea, resistente e perpendicular ao plano do segmento, sendo estas decorrentes sobre os eixos seguintes, no lado basioscópico. Lâmina herbácea, deltóide, 3- a 4-pinado-pinatífida; pínulas mais ou menos pubescentes abaxialmente, tricomas integralmente acastanhados ou pardos (escurecidos), raramente subopacos ou esbranquiçados; nervuras estéreis na superfície inferior, usualmente com extremidades delgadas. Soros com indúsio maduro em forma de taça profunda a raramente cilíndrico.

Material examinado: BRASIL. São Paulo: Bady Bassit, Fazenda Nossa Senhora de Fátima, ca. 3km da Rod. BR-153, 11/III/1995, Nonato \& Pietrobom-Silva 78 (SJRP); Cedral, 23/VI/1995, Soares 20 (SJRP); Jaci, rodovia vicinal Mirassol-Jaci, ca. $1 \mathrm{~km}$ de Jaci, 14/VIII/1996, Pietrobom-Silva 3403 (SJRP); Mirassol, 06/XII/1987, Salino 224 (UEC); idem, 11/III/1989, Salino 232 (UEC); idem, X/1994, Torres \& Oliveira 04 (SJRP).

\section{Lindsaea Dryand.}

Planta terrestre, rupestre ou epífita. Rizoma decumbente e curto-reptante, ou ainda, longo-reptante, comportando escamas lanceoladas, castanho-claras e usualmente 


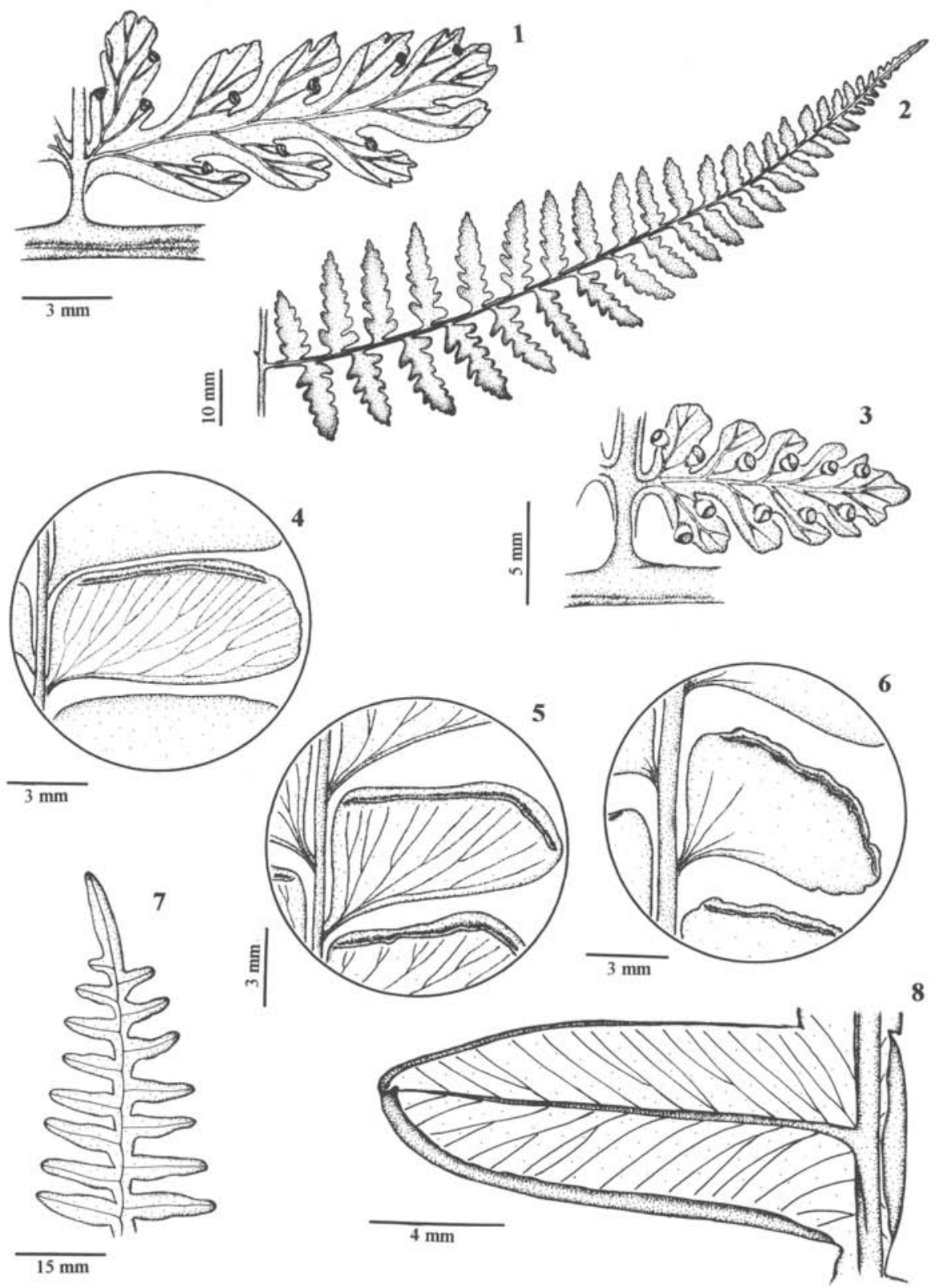

Figuras 1-8. 1. Dennstaedtia cicutaria, pínula fértil. 2-3. D. globulifera. 2. Aspecto geral de pina. 3. Pínula fértil (notar aletas decorrentes). 4. Lindsaea lancea, pínula fértil evidenciando soros marginais. 5. L. quadrangularis, idem. 6. L. stricta, idem. 7-8. Pteridium aquilinum var. arachnoideum. 7. Ápice de pina. 8. Pínula estéril, com seu padrão de venação. 
intergradando a rígidos tricomas. Frondes monomorfas, raro dimorfas; de tamanho variável, ca. $15-100 \mathrm{~cm}$ compr. Lâmina membranácea a coriácea, pinada a bipinada (raramente subtripinada ou 3-pinada), glabra; nervuras anastomosadas com vênulas secundárias inclusas livres ou nervuras livres, simples ou furcadas. Soros submarginais a marginais, sendo tipicamente estendido ao longo da margem das pinas ou pínulas, podendo ser curto lateralmente, sem paráfises, portando freqüentemente tricomas similares aos da lâmina; indúsio fixado lateralmente, extrorso, com abertura dirigida para fora, longo em algumas espécies.

Gênero pantropical e extratropical, com ca. de 150 espécies, sendo que 45 delas ocorrem nas Américas (Tryon \& Tryon 1982). As espécies ocorrentes nas Américas foram revisadas por Kramer (1957).

No Brasil, o centro primário de diversidade e endemismo do gênero Lindsaea situa-se na região de Roraima (em formações arenosas) com 27 espécies, sendo 14 endêmicas. O sudeste brasileiro compreende o segundo centro com 13 espécies, sendo três endêmicas (Tryon \& Tryon 1982).

\section{Chave para identificação das espécies de Lindsaea}

1. Tecido laminar com textura coriácea, nervuras ocultas, indúsio erodido a lacerado 3. L. stricta

1. Tecido laminar com textura herbácea, nervuras um pouco evidentes, indúsio inteiro 2

2. Estípite estramíneo a castanho; pínulas basais nitidamente reduzidas .....

2. L. quadrangularis

2. Estípite nigrescente ou verde escuro; pínulas basais levemente reduzidas, sendo na maioria, de dimensões semelhantes às medianas ... 1. L. lancea

1. Lindsaea lancea (L.) Bedd., Ferns Brit. India Suppl.: 6. 1876.

Adiantum lancea L., Sp. pl. ed. 2, II: 1557. 1763.

Lindsaea falcata Dryand. var. lancea (L.) Jenman, W. Ind. Gui. F.: 74. 1899.

Lindsaea trapeziformis Baker in Mart., Fl. Bras. I (2): 355. 1870.

Lindsaea lancea (L.) Bedd. var. subtripinnata Rosenst., Hedwigia 46: 79. 1906. Fig. 4

Planta terrestre. Rizoma reptante (algumas vezes longo-reptante), 2-3mm diâm.; escamas um pouco lanceoladas, longo-acuminadas. Estípite nigrescente, preferencialmente, podendo ser verde-escuro. Lâmina 1 ou 2-pinada; textura herbácea, nervuras pouco evidentes; pínulas basais levemente reduzidas, sendo na maioria, de dimensões semelhantes às medianas; pínulas apicais reduzidas; segmento terminal bem definido, com os segmentos adjacentes pouco reduzidos; raque da lâmina alado adaxialmente e raques das pinas, em geral, alados adaxial e abaxialmente. Soros marginais; indúsio inteiro.

Material examinado: BRASIL. São Paulo: Borborema, ca. 500m do cruzamento da SP-304 com SP-333, 21/XII/1996, Pietrobom-Silva 3903 (SJRP); idem, idem, 21/ 
XII/1996, Pietrobom-Silva 3935 (SJRP); Cosmorama, 02/XII/1994, Barbosa \& Forster 19 (SJRP); Cosmorama, Fazenda Borges, 04/XI/1995, Borges \& Aureliano 26 (SJRP); Nhandeara, VI/1996, Nonato 28 (SJRP); Zacarias, Fazenda Santa Irene, 21/II/1997, Siqueira 102 (SJRP).

2. Lindsaea quadrangularis Raddi, Opusc. Sci. Bol. 3: 294. 1819.

Lindsaea lancea (L.) Bedd. var. quadrangularis (Raddi) Rosenst., Hedwigia 46: 80. 1906.

Fig.5

Planta terrestre. Rizoma reptante, 1,5-3mm diâm., escamas lanceoladas, acuminadas. Estípite estramíneo a castanho. Lâmina bipinada; textura herbácea, nervuras pouco evidentes; pínulas, na maioria, estreitadas; as basais e superiores nitidamente reduzidas; segmento terminal bem definido, com os segmentos adjacentes pouco reduzidos; raque da lâmina e raques das pinas, em geral, angulares abaxialmente. Soros marginais; indúsio inteiro.

Material examinado: BRASIL. São Paulo: José Bonifácio, estrada Municipal José Bonifácio-Nova Aliança, Fazenda Santa Clara (entre os córregos Jacaré e Fartura), 22/II/1992, Pietrobom-Silva 118 (SJRP); idem, idem, 06/V/1997, Siqueira et al. 123 (SJRP).

3. Lindsaea stricta (Sw.) Dryand., Trans. Linn. Soc. London 3: 42. 1797.

Adiantum strictum Sw., Prodr.: 135. 1788.

Lindsaea brasiliensis Desv., Berl. Mag. 5: 330. 1811.

Lindsaea stricta (Sw.) Dryand. var. tripinnata Hook., Spec. fil. I: 216. 1844.

Lindsaea dentata Fée, Crypt. vasc. Brés. II: 20. 1872/73.

Fig. 6

Planta terrestre. Rizoma reptante, 1-3mm diâm.; escamas um pouco lanceoladas, longo-acuminadas. Estípite estramíneo a castanho-claro. Lâmina 1 ou 2-pinada (raramente 3-pinada); textura em geral coriácea; nervuras frequentemente ocultas na superfície abaxial; pínulas basais semelhantes às medianas; pínulas apicais reduzidas; segmento terminal pequeno, mais ou menos confluente com os segmentos laterais adjacentes reduzidos; raque da lâmina e raques das pinas arredondados a angulares abaxialmente e sulcados adaxialmente. Soros submarginais a marginais; indúsio usualmente bem erodido a lacerado.

Material examinado: BRASIL. São Paulo: Cedral, Estrada de Ferro Fepasa, V/ 1992, Andrade et al. 140 (SJRP).

III. Pteridium Gleditsch ex Scop.

Gênero que ocorre nos trópicos e regiões temperadas, com uma única espécie e 12 variedades geográficas, revisado por Tryon (1941), que reconhece seis variedades na América. Representado na região por: 
Pteridium aquilinum (L.) Kuhn var. arachnoideum (Kaulf.) Brade, Zeitschrift Deut. Ver. Wissen Kunst., São Paulo. 1: 56. 1920.

Pteris aquilina L., Sp. pl. 2: 1075. 1753.

Pteris arachnoidea Kaulf., Enum. fil.: 190. 1824.

Fig. 7-8

Plantas terrestres. Rizoma longo-reptante com tricomas pluricelulares, sem escamas, ca. 3,0cm diâm. Frondes monomorfas, medindo até 7,0m compr., $80 \mathrm{~cm}$ larg., retas, podendo ser escandentes. Lâmina em geral coriácea, 2- a 4-pinado-pinatífida, pubescente a raramente lisa; pinas decompostas, largas; nervuras livres, simples ou furcadas. Soros marginais, geralmente contínuos e alongados, paráfises ausentes; esporângios dispostos entre um indúsio externo falso (porém funcional), formado pela margem modificada retroflexa, e outro indúsio interno verdadeiro (porém não funcional), membranoso, que pode ter vários graus de desenvolvimento.

Material examinado: BRASIL. São Paulo: Nhandeara, VI/1994, Nonato 27 (SJRP); Nova Aliança, Distrito Nova Itapirema, 04/X/1991, Amorim 108 (SJRP).

\section{Agradecimentos}

Os autores registram seu reconhecimento aos curadores dos herbários citados pela atenção e paciente cooperação; aos assessores anônimos, pelas sugestões e aos coletores do material em que este trabalho se baseia; ao CNPq, pela concessão de bolsa de Iniciação Científica ao primeiro Autor, e de Produtividade em Pesquisa ao segundo Autor. Trabalho desenvolvido no Departamento de Botânica da Universidade Estadual Paulista - UNESP, Campus de São José do Rio Preto, agradecendo-se todo o apoio recebido.

\section{Referências bibliográficas}

Angely, J. 1970. Flora analítica e fitogeográfica do Estado de São Paulo. Ed. 1. Edição Phyton, São Paulo.

Brade, A. C. 1920. Die Farnflora der Umgebung der Stadt São Paulo. Zeitschrift, Deutscher Verein für Wissenschaft und Kunst, São Paulo. I: 39-61.

Kramer, K. U. 1957. A revision of the genus Lindsaea in the new world. Acta Botanica Neerlandica 6: 97-290.

Pereira-Noronha, M. R. 1989. Formas de vida e reprodução em pteridófitas. Tese de Doutorado. UNESP, Rio Claro

Prado, J. 1997. Estudo de biodiversidade de espécies de pteridófitas do Estado de São Paulo. Fundação André Tosello. [http://www.bdt.org.br/bdt/biotasp/pterid.htm].

Salino, A. 1993. Flora pteridofítica das matas ciliares da bacia do Rio Jacaré-Pepira, Estado de São Paulo, Brasil. Dissertação de Mestrado. UNICAMP, Campinas.

Salino, A. 1996. Levantamento das pteridófitas da Serra do Cuscuzeiro, Analândia, SP, Brasil. Revista Brasileira de Botânica 19(2): 173-178.

Tryon, R. M. 1941. A revision of the genus Pteridium. Rhodora 43: 1-31.

Tryon, R. M. 1960. A review of the genus Dennstaedtia in America. Contribution from the Gray Herbarium 187: 23-52.

Tryon, R. M. \& Stolze, R. G. 1989. Pteridophyta of Peru part II. 13. Pteridaceae - 15. Dennstaedtiaceae. Fieldiana Botany 22: 1-128. 
Tryon, R. M. \& Tryon, A. F. 1982. Ferns and allied plants with special reference to Tropical America. Springer Verlag, New York.

Usteri, A. 1911. Flora Der Umgebung Der Stadt São Paulo. Gustav Fischer (ed.), Jena.

Windisch, P. G. 1992. Pteridófitas da região norte-ocidental do Estado de São Paulo: guia para estudo e excursões. $2^{*}$ edição. UNESP, São José do Rio Preto.

Windisch, P. G. 1996. Towards assaying biodiversity in Brazilian pteridophytes. Pp. 109-117. In: C. E. M. Bicudo \& N. Menezes (eds.), Biodiversity in Brazil: a first approach. CNPq, São Paulo. 